\title{
De las Juntas de Comercio al Consulado. Los comerciantes rioplatenses y sus estrategias corporativas, 1779-1794
}

\author{
Javier Gerardo Kraselsky \\ Universidad Nacional de La Plata (UNLP)
}

\begin{abstract}
El propósito de este trabajo es analizar los objetivos económicos de los comerciantes rioplatenses en el último cuarto del siglo XVIII y las estrategias abordadas por sus actores para alcanzarlos. Se estudian aquí las Juntas de Comercio como ámbito de negociación colectiva en donde los comerciantes defendian sus intereses desde 1779, y las razones que impulsaron su transformación en el Consulado de Comercio de Buenos Aires en 1794. Estos comerciantes habrían gestionado el Consulado debido a su necesidad de ampliar los beneficios jurisdiccionales y de resguardar su posición privilegiada amenazada por otros sectores de poder como el gremio de los hacendados y los comerciantes que integraban el Consulado de Lima.

Palabras clave: Comerciantes, Juntas de Comercio, Borbones, Consulado de Buenos Aires.

The purpose of this paper is to analyze the economic objectives of rioplatense merchants during the last quarter of the eighteenth century and the strategies they used to achieve them. The main points of this analyzes are the Juntas de Comercio, as scenario of collective negotiation where the merchants defended their interests, and the reasons which triggered their transformation in the Consulado of Buenos Aires in 1794. Must have petitioned for the Consulado as a consequence of their need to widen their jurisdictional benefits and to protect their privileged position threatened by other power sectors such as the landowners corporation and the Consulado of Lima's merchants.
\end{abstract}

Keywords: Merchants, Juntas de Comercio, Consulado, Bourbon Crown.

\section{Introducción}

Se pretenden analizar los objetivos económicos de los comerciantes rioplatenses de 1775 a 1800, y para ello se propone analizar las Juntas de Comercio como ámbito de negociación corporativa y de representación específica de los intereses de los comerciantes locales. En dichas Juntas, desde 1779, se conformó una organización política permanente compuesta por apoderados que impulsaron estrategias mercantiles para obtener beneficios colectivos. Mediante estas estrategias los comerciantes promovieron 
la conformación del Consulado de comercio de Buenos Aires, finalmente fundado en 1794.

De este modo, mediante el estudio de las Juntas se examinan las relaciones entre el cuerpo mercantil local, respecto a las autoridades centrales y a otros cuerpos que constituyeron la sociedad del Antiguo Régimen. Desde esta perspectiva, se intentan comprender las estrategias mercantiles utilizadas por los actores locales para consolidar su posición hegemónica y los medios de organización política impulsados para ello. Se aborda a las Juntas como organización particular, con su propia dinámica interna de funcionamiento, y no meramente como un paso coyuntural en la formación del Consulado de comercio. ${ }^{1}$

La Corona, en el contexto de las reformas borbónicas, ante su creciente necesidad de contar con ingresos monetarios para el sostenimiento de su corte y la financiación de sus disputas internacionales, promovió el fortalecimiento de las estructuras monárquicas y la resignificación de sus vínculos con las elites locales. ${ }^{2}$ Así, mediante este proyecto de centralización corporativa $a^{3}$ los Borbones estimulaban la conformación de cuerpos mercantiles locales con quienes negociar las obligaciones mutuas. De ahí que,

1 Sólo algunos trabajos abordan el tema de las Juntas de Comercio. Véase Mariluz Urquijo, José María: "Solidaridades y antagonismos de los comerciantes de Buenos Aires a mediados del setecientos", Investigaciones y Ensayos, n. 35, Buenos Aires, 1987, págs. 47-85; Socolow, Susan: Los mercaderes del Buenos Aires virreinal: familia y comercio, Ediciones de la Flor, Buenos Aires, 1991, págs. 129-158.

2 Acerca de las iniciativas borbónicas y su vínculo con los actores locales existen numerosos trabajos. Véase entre otros Brading, David: Orbe Indiano. De la Monarquía católica a la República criolla, 1492-1867, Fondo de Cultura Económica, México, 1998, págs 503-529; Gelman, Jorge: "La lucha por el control del Estado: administración y elites en Hispanoamérica", en Tándeter, Enrique (dir.) e Hidalgo Lehuedé, Jorge (co-dir.): Procesos americanos hacia la redefinición colonial, Ediciones de la UNESCO/Editorial Trotta, (Historia General de América Latina, Tomo IV), Madrid, 2000, págs. 251-264; Halperin Donghi, Tulio: Reforma y Disolución de los Imperios Ibéricos, 1750-1850. (Historia de América Latina, Tomo III), Alianza, Madrid, 1985, págs. 17-74; Lynch, John: El Siglo XVIII, Crítica, Barcelona, 1991, págs. 295-336; Moutoukias, Zacarías: "Redes, Autoridad y Negocios: Racionalidad empresaria y consenso colonial en Buenos Aires (Segunda mitad del siglo XVIII)", Annales, 47, 4-5, Paris, julio-octubre, 1992, págs. 899-915; Jumar, Fernando: "El precio de la fidelidad. La Guerra de Sucesión en el Río de la Plata, los intereses locales y el bando borbón”, en Molinié, Annie y Alexandra Merle (dirs.): L'Espagne et ses guerres. De la fin de la Reconquête aux guerres de l'Indépendance, Presses de l'Université Paris-Sorbonne, París, 2004, págs. 203-236; del mismo autor: "Los rioplatenses, el Río de la Plata y el poder central en el siglo XVIII. Hombres de Antiguo Régimen en la lucha contra la Modernidad. Un Ensayo", en Simposio Internacional La formación de la cultura iberoamericana. Siglo XVIII, Centro de Estudios Latinoamericanos, Universidad Católica de Eichstätt, Alemania, 2003, págs. 1-51.

3 Kraselsky, Javier: Los comerciantes rioplatenses y sus estrategias de asociación corporativas. Las Juntas de Comercio en el siglo XVIII, (Inédita), Universidad Nacional de Tres de Febrero, Buenos Aires, 2005, 217 págs. 
en el Río de la Plata, el reconocimiento de la estructura permanente de apoderados de las Juntas de Comercio desde 1779 y posteriormente la cesión del Consulado en 1794 habría sido para la Corona un medio de asegurarse la lealtad de la elite mercantil y, de ese modo, los recursos monetarios de sus dominios ultramarinos.

Con ello, la resignificación de los lazos entre comerciantes y Corona no se centraba en la sumisión de los primeros, sino que revelaba la negociación entre el poder central y las elites locales. Es decir, la nueva fórmula de relaciones implicaba un vínculo más estrecho entre cuerpos interdependientes que se necesitaban mutuamente. Los comerciantes conformaron de este modo un cuerpo autónomo que integraba el Estado monárquico con su propia fuerza de negociación y margen de poder relativo para defender sus intereses y consolidar sus privilegios.

Este trabajo intentará demostrar, entonces, que el Consulado de comercio de Buenos Aires se habría originado en el último cuarto del siglo XVIII como consecuencia de un doble estímulo, tanto de los monarcas como de los propios actores locales que negociaban los términos de su vínculo en mutuo beneficio. En este sentido, si bien las Juntas de Comercio y su estructura política permanente habían funcionado como ámbito de negociación exitoso desde 1779, más tarde y en un nuevo contexto, sus actores poderosos habrían necesitado un mayor margen de acción para no perder sus privilegios. Este margen sólo podía brindarlo la institucionalización de ese gremio en un Consulado.

Desde esta perspectiva, por un lado, la Corona habría fomentado la conformación de un cuerpo mercantil local con el objeto de asegurarse la obtención de ingresos monetarios de territorios lejanos a su control directo, cediendo para ello ventajas comerciales a sus actores poderosos. Los reyes proyectaban una centralización política monárquica y un fortalecimiento corporativo de los sectores locales poderosos. Con ello habrían estimulado la formación de cuerpos y Consulados de comercio por medio de los cuales canalizarían la negociación con las elites locales.

Por otra parte, la elite de los comerciantes rioplatenses, que poseía la hegemonía mercantil mediante el control de las Juntas de Comercio y su estructura representativa permanente desde 1779 , habría necesitado desde principios de la década de 1790 fortalecer su posición para resguardar sus privilegios frente a otros cuerpos constitutivos de la sociedad. La amenaza a esa hegemonía, manifestada por los comerciantes del Consulado de Lima por un lado y por el gremio de los hacendados por otro, habría constituido 
la razón principal que impulsó a los actores mercantiles a la elaboración de estrategias para la institucionalización legal de su cuerpo de comercio.

\section{Las Juntas de Comercio y sus estrategias de acción corporativa}

Estas Juntas constituyeron una organización específica y particular de los comerciantes que, al menos en el Río de la Plata, funcionaron como canal exitoso para la negociación de ventajas corporativas. ${ }^{4}$ Fueron reuniones de comerciantes en las cuales se dirimieron conflictos colectivos y elaboraron estrategias conjuntas de acción frente a la Corona y el resto de los actores corporativos de la sociedad del siglo XVIII.

Tras el Reglamento de Libre Comercio de 1778, que establecía la posibilidad de fundar nuevos Consulados, ${ }^{5}$ en Buenos Aires y en el contexto de ampliación de los circuitos mercantiles, ${ }^{6}$ los comerciantes promovieron en primera instancia la formación de una estructura política permanente de apoderados que representara al cuerpo mercantil. ${ }^{7}$ Con ello, inicialmente los actores prefirieron la formalización de una fórmula conocida al establecimiento de un Consulado propio. Así, las Juntas de Comercio y su representación por apoderados, que fueron recursos practicados desde mediados del siglo XVIII, ${ }^{8}$ adquirieron, desde 1779, estabilidad y representatividad de toda la corporación.

4 Me centraré en Buenos Aires, núcleo de un espacio mayor que Fernando Jumar denomina complejo portuario rioplatense y que estaba integrado, además de Buenos Aires, por Montevideo, Colonia de Sacramento y una cantidad de desembarcaderos clandestinos sobre la costa de Buenos Aires. Véase Jumar, Fernando: Le commerce atlantique au Río de la Plata, 1680-1778, Presses Universitaires du Septentrion, Villeneuve-d'Asq, 2002, 2 tomos.

5 Según su artículo 53 “...en todos los puertos habilitados de España donde no huviere Consulados de Comercio, se formen ahora con arreglo á las Leyes de Castilla é Indias...”. Véase Documentos para la Historia Argentina, (en adelante DHA), Facultad de Filosofía y Letras, Buenos Aires, 1913-1919, Tomo VI, pág. 35.

6 Véase, entre otros, Silva, Hernán Asdrúbal (dir.): Navegación y Comercio rioplatense, I, Universidad Nacional del Sur, Bahía Blanca, 1996; Garavaglia, Juan Carlos: "El ritmo de la extracción de metálico desde el Río de la Plata a la Península, 1779-1783", Revista de Indias, 36, 143/144, enerojunio de 1976, págs. 247-268.

7 Mediante una Junta General en la que participaron 54 comerciantes, se erigió una organización permanente compuesta por tres apoderados de comercio. Para esta función fueron elegidos Martín de Sarratea, Manuel Rodríguez de la Vega y Bernardo Sancho Larrea. Esta organización funcionó hasta 1794 y sólo en una oportunidad se intentó reemplazar a los dos últimos. Esto sucedió en las frustradas Juntas realizadas el 20 y el 24 de octubre de 1789. Véase Kraselsky, Javier: Los comerciantes rioplatenses..., págs. 166-170.

8 Mariluz Urquijo, José María: "Solidaridades y antagonismos...”, págs. 47-85. 
En el interior de las Juntas, la elite mercantil pudo desarrollar y planificar sus estrategias con el objeto de consolidar su hegemonía económica. Con ello, los comerciantes poderosos tuvieron la capacidad de obtener ingresos de toda la comunidad, asegurando a la Corona parte de lo recaudado a cambio de una serie de privilegios comerciales. ${ }^{9}$ Esta estructura representativa contaba con el apoyo de la comunidad mercantil debido a que, a cambio de su adhesión, podían obtener beneficios laterales como reducciones y dilaciones en los pagos impositivos a la Corona. ${ }^{10}$

De este modo, la Junta, que desde 1779 contaba con mecanismos particulares de funcionamiento, ${ }^{11}$ fue el ámbito en el cual la elite mercantil definía sus estrategias corporativas que le permitían conservar su hegemonía regional. Así, en el seno de las Juntas se elaboraban representaciones colectivas designándose a los mismos apoderados, a otros comerciantes o a un consorcio integrado por varios de ellos, para gestionar lo allí resuelto. $^{12}$

Las Juntas de Comercio y sus apoderados permanentes por entonces cumplieron, desde 1779 hasta 1794, muchas funciones como Consulado "de hecho". Por ello, no pueden ser analizadas como efímero escalón hacia esa institución, sino como una organización compleja que tuvo como una de sus funciones, y no la única, la gestión ante las autoridades de la creación de dicha corporación mercantil.

Ahora, si las Juntas constituían una institución semiformal exitosa, y funcionaban como espacio de negociación de los actores locales frente a la Corona, es preciso cuestionarse sobre las motivaciones que impulsaron la legalización de su estructura política en el Consulado en 1794. Como aquí se sostiene, una respuesta puede buscarse en la rearticulación de las relaciones entre la Corona y los actores locales en el último tercio del siglo XVIII.

9 Los aportes monetarios de los comerciantes para hacer efectivos los donativos reales en 1786 y 1792, ejemplifican la capacidad de la elite para establecer las modalidades de la recaudación. Estos donativos revelan también que los aportes de la comunidad a la Corona eran indispensables en la negociación por la creación del Consulado. Kraselsky, Javier: Los comerciantes rioplatenses..., págs. 108-117.

10 Tal es el caso de las dilaciones en el pago de las alcabalas de segunda venta por los comerciantes poseedores de tiendas en el período 1787-1788 y 1789-1792. Ibídem, pags. 89-99.

11 Las Juntas se efectuaban de modo irregular, dependiendo de los problemas que se suscitaran. En el período entre 1779 y 1794 se reunieron numerosas Juntas a las que asistieron entre 12 y 113 miembros. Existían diferentes modos de convocarla y diferentes razones para ello. Ibídem, pags. 34-42. 12 Ibídem, pág. 33. 
Así, aunque ya desde 1779 se solicitaba la formación del Consulado ${ }^{13}$ y a partir de 1784 se impulsaba su legalización con mayor fuerza, ${ }^{14}$ sólo después de 1790 las demandas fueron más explícitas. En Buenos Aires, como en otras regiones, se apelaba para gestionar el Consulado a las Juntas de Comercio o a las representaciones de los apoderados. ${ }^{15}$ De este modo, y en el marco de la formación de numerosos cuerpos mercantiles en diversas regiones americanas, ${ }^{16}$ el Consulado de Buenos Aires se conformó en $1794 .{ }^{17}$

13 Archivo General de la Nación, (en adelante AGN), IX 37-7-6, expte 20, f. 4.

14 Se produjeron al menos tres Juntas con este propósito, la primera el 7 de julio de 1785 de la que participaron 56 comerciantes y en la cual nombraron representantes para su gestión en Madrid. Las dos restantes fueron el 21 de agosto y el 6 de septiembre de 1790, con 113 y 103 comerciantes respectivamente. Véase Tjarks, Germán: El Consulado de Buenos Aires y sus proyecciones en la Historia del Río de la Plata, Instituto de Historia Argentina "Doctor Emilio Ravignani”, Buenos Aires, 1962, tomo I, págs. 46-57; Navarro Floria, Pedro: El Consulado de Buenos Aires. 1790-1806, Ediciones de la Universidad Complutense de Madrid, Madrid, 1992, págs. 45-69; Dalla Corte, Gabriela: Vida i mort d'una aventura al Riu de la Plata. Jaime Alsina i Verjés, 1770-1836, Publicaciones de L'abadia de Montserrat, Barcelona, 2000, págs. 51-70; AGN, Consulado de Buenos Aires, Antecedentes, Actas y Documentos, Kraft Ltda., S.A., 1936, tomo I, págs. 11-192.

15 Para Burgos y Bilbao, Basas Fernández, Manuel: El Consulado de Burgos en el siglo XVI, Consejo Superior de Investigaciones Científicas, Escuela de Historia Moderna, Madrid, 1963, pág. 33. Para Sevilla, Ruiz Rivera, Julián y García Bernal, Manuela C.: Cargadores a Indias, Colecciones MAPFRE 1492, Madrid, 1992, pág. 53. Para Málaga, Bejarano, Francisco: Historia del Consulado y de la Junta de Comercio de Málaga (1785-1859), Consejo Superior de Investigaciones Científicas, Instituto Jerónimo Zurita, Madrid, 1947, págs. 10-13. Respecto a los consulados americanos posteriores al Reglamento de 1778, véase Ibarra, Antonio: "El Consulado de Comercio de Guadalajara: entre la modernidad institucional y la obediencia a la tradición, 1795-1818”, en Valle Pavón, Guillermina del (coord.): Mercaderes, comercio y consulados de Nueva España en el siglo XVIII, Instituto Mora, México, 2003, págs. 310-333; del mismo autor: "Mercado, élite e institución: El Consulado de Comercio de Guadalajara y el control corporativo de las importaciones en el mercado interno novohispano", en: Hausberger, Bernd e Ibarra, Antonio (eds.): Comercio y poder en América colonial. Los Consulados de comerciantes, siglos XVII-XIX, Biblioteca Ibero-Americana, Madrid, 2003, págs.145-170.

16 Se conforman en 1793 los Consulados de Caracas y Guatemala; luego Buenos Aires (1794), también La Habana (1794), Guadalajara, Veracruz, Cartagena de Indias y Chile (1795). Véase Cruz Barney, Óscar: El régimen jurídico de los consulados de comercio indianos: 1784-1795, Universidad Nacional Autónoma de México, México, 2001; Valle Pavón, Guillermina del (coord.): Mercaderes, comercio y consulados... Hausberger, Bernd e Ibarra, Antonio (eds.): Comercio y poder en América colonial...

17 Luego de la sólida obra de Germán Tjarks: El Consulado de Buenos Aires..., se produjeron pocos estudios sobre el tema. Véase Navarro Floria, Pedro: El Consulado..., y del mismo autor "Ilustración y radicalización ideológica en el Consulado de Buenos Aires (1755-1810)", Revista de Indias, vol. XLIX, $\mathrm{n}^{\circ}$ 186, Madrid, 1989, págs. 411-422; otros trabajos se refieren lateralmente a este tema, véase Socolow, Susan: Los mercaderes del Buenos Aires virreinal...; Gabriela Dalla Corte: Vida i mort ... 


\section{Viejos problemas: comerciantes de Lima y Buenos Aires}

Las relaciones de competencia entre Buenos Aires y Lima existían desde tiempo atrás y habrían sido una de las razones principales que llevaron a los comerciantes porteños a pedir el establecimiento de un Consulado propio. ${ }^{18}$ La cuestión del diputado del Comercio en 1752-1756, es una muestra de intereses no siempre coincidentes y de la tensión latente que generaba el dominio de los espacios locales y la ruta hacia Chile y el Alto Perú. ${ }^{19}$

No obstante, también existieron intereses comunes que manifestaban la presencia de relaciones amistosas entre actores de ambos espacios. ${ }^{20}$ Así, por ejemplo, muchos de los individuos del comercio rioplatense aparecieron en más de una ocasión representando al Consulado de Lima. ${ }^{21}$ Los individuos

18 Este tema ha sido analizado profundamente por numerosos autores desde distintas perspectivas. Para una visión clásica, véase Céspedes del Castillo, Guillermo: "Lima y Buenos Aires. Repercusiones económicas y políticas de la creación del virreinato del Plata," Anuario de Estudios Americanos, III, Sevilla, 1946, págs. 667-874; y del mismo autor: La Avería en el Comercio a Indias, Escuela de Estudios Hispano-Americanos de la Universidad de Sevilla, Sevilla, 1945; Levene, Ricardo: Investigaciones acerca de la Historia Económica del Virreinato del Plata, Academia Nacional de la Historia, Buenos Aires, 1962.

19 El problema de la prohibición de libre internación de mercancías por Buenos Aires, y las licencias reales brindadas a comerciantes hasta el establecimiento del "Auto de Libre Internación" en 1777 han sido analizados, entre otros, por Céspedes del Castillo, Guillermo: La Avería..., págs. 115 y ss.; Levene, Ricardo: Investigaciones..., págs. 255 y ss.; Mariluz Urquijo, José María: "Solidaridades y antagonismos...", págs 58-71; del mismo autor: "El Diputado del Consulado de Lima en Buenos Aires", Academia Nacional de la Historia. Memoria del Cuarto Congreso Venezolano de Historia, tomo II, Caracas, 1983, págs. 331-355; y "Lima y Buenos Aires frente a la prohibición de internación durante la segunda mitad del siglo XVIII”, en: Sobre el Perú. Homenaje a José Agustín de la Puente Cándamo, Pontificia Universidad Católica del Perú, Facultad de Letras y Ciencias Humanas, tomo II, Lima, 2002, págs. 791-800; Barba, Enrique: Don Pedro de Cevallos, Instituto de Cooperación Iberoamericana, Madrid, 1988, págs. 271-301; Nortman, Irene: "Aspectos de la evolución de la jurisprudencia comercial en el Río de la Plata hasta la erección del Consulado", Boletín de la Academia Nacional de la Historia, vol. XXVI, Buenos Aires, 1952, págs. 475-495; Moutoukias, Zacarías: "Las formas complejas de la Acción política: Justicia corporativa, faccionalismo y redes sociales (Buenos Aires, 17501760)", Jahrbuch für Geschichte von Staat, Wirtschaft und Gesellschaft Lateinamerikas, 39, Colonia, 2002, págs, 69-102.

20 Véase Parrón Salas, Carmen: De las Reformas borbónicas a la República: El Consulado y el comercio marítimo de Lima, 1778-1821, Imprenta de la Academia Nacional del Aire, Murcia, 1995; Mazzeo, Cristina: El comercio libre en el Perú. Las estrategias de un comerciante criollo. José Antonio de Lavalle y Cortés, Conde de Premio Real. 1777-1815, Pontificia Universidad Católica del Perú, Lima, 1994.

21 Tal es el caso de Eugenio Lerdo de Texada y Bernardo Sancho Larrea, que fueron apoderados del Consulado de Lima en Buenos Aires en 1777, al tiempo que participaron de demandas de los comerciantes locales. El primero solicitando desde el Cabildo la Libre Internación, y el segundo como apoderado electo en la Junta de Comercio de 1779. 
no siguieron un patrón fijo de comportamiento, sino que actuaron de acuerdo a sus conveniencias coyunturales. Y, en el último cuarto del siglo XVIII, los comerciantes rioplatenses agrupados en su cuerpo local, percibieron la oportunidad de una jurisdicción propia y la consolidación de un canal de diálogo directo con la Corona, con los beneficios que esto conllevaba.

En este apartado se estudian una serie de Juntas de Comercio que revelan tensiones entre los actores mercantiles por la jurisdicción y por la administración de poder. Así, los gravámenes promovidos desde finales de 1777 por el Consulado de Lima, que solicitaba la devolución del préstamo monetario de un millón y medio de pesos que su comunidad mercantil había aportado a la expedición de Cevallos contra los portugueses en Colonia de Sacramento, ${ }^{22}$ a través de la imposición de derechos aduaneros ${ }^{23}$ constituyeron una de las razones que estimularon a los comerciantes de Buenos Aires a promover un ámbito mercantil específico que pudiera contrarrestar tales medidas. En este sentido, en Buenos Aires, que desde la creación del Virreinato del Río de la Plata constituía la capital de la nueva jurisdicción, se elaboraron respuestas a tal reclamo, que fueron manifestadas tanto por la Real Hacienda $\mathrm{H}^{24}$ como por las representaciones de los apoderados del comercio local. ${ }^{25}$

La iniciativa del Consulado de Lima pareció haber fracasado en primera instancia. Sin embargo, esto no significó que su reclamación fuera olvidada por quienes impulsaban el aumento de derechos aduaneros. Nuevamente en el año 1783, el Consulado limeño volvió a insistir con la devolución de lo prestado mediante gravámenes aduaneros sobre el Río de la Plata. ${ }^{26} \mathrm{El}$ rey concedió esta vez a Lima aquello que solicitaba y estableció la exacción del 1 y $3 \frac{4}{4} \%$ en la plata y $1 / 2 \%$ en el oro de todos los cau-

22 Los avatares de esta situación fueron abordados por Tjarks, Germán: El Consulado de Buenos Aires..., Tomo II, págs. 490-501.

23 AGN, IX 30-9-4, expte 6. Con dicho objeto, se realizaron dos Juntas Generales en Lima que resolvieron pedir al rey la imposición de 1 y $3 / 4$ para la plata y $1 / 2$ en el oro embarcados por los puertos del Virreinato. La primera fue el 8 de septiembre de 1777, pero debido a que entre los puertos mencionados no aparecían detallados los del Río de la Plata, se convocó una nueva Junta el 30 de diciembre de 1777 en la que estos fueron incluidos explícitamente.

24 Ibídem, f. 34/35. Aludían que "por que Sufren sus moradores otras ynfinitas, sre. Sus yntereses, y sus personas" debido a la crisis de su comunidad mercantil por la prohibición de libre internación. Además se referían a que "divididos los Virreinatos parece que no puede haver vastante autoridad, en el Superior Gov.no de uno, para ampliar estas cargas al otro...".

25 Ibídem, 6, f. 36 vta. Para ello, mencionaron la prohibición del Reglamento de imponer tales gravámenes ya que era "hir contra las Piadosas Intenciones del Soverano...".

26 AGN, IX 4-7-3, expte 3, f. 1. A su argumento original de la erogación para financiar los gastos de la expedición de Cevallos contra los portugueses, se sumaron otros caudales supletorios. 
dales que salieran de Buenos Aires y Montevideo. ${ }^{27}$ Como era de esperar, los actores locales reaccionaron ante tal medida. Así, tanto el Cabildo ${ }^{28}$ como los comerciantes reunidos en Junta defendieron sus intereses protestando contra la decisión real. ${ }^{29}$

Con este propósito, los apoderados impulsaron una serie de escritos que manifestaban su participación y financiación en la defensa de la ciudad de Buenos Aires,$^{30}$ no sólo circunscrita a la zona portuaria sino que se extendía a otros territorios como las Islas Malvinas. ${ }^{31}$ Es decir, el cuerpo de comerciantes manifestaba haber brindado ayuda a la Corona, con lo cual aspiraba a conservar su posición como cuerpo local leal a la causa real y, por ello, fuera del alcance de tales aumentos..$^{32}$ Así apelaban tanto a su fidelidad hacia el monarca, como a su legitimidad como cuerpo representativo de los intereses locales.

Los apoderados del comercio manifestaron que el pago de estos nuevos derechos sobre los metales se efectuaba "en continuacion de su seguido sistema de deprimir á este comercio, y hacerle dependientes de sus migajas...". ${ }^{33}$ Estos argumentos no eran nuevos, desde tiempo atrás los comerciantes locales elevaban memoriales y representaciones manifestando la conveniencia de incorporar a Buenos Aires como nexo hacia la ruta altoperuana, en reemplazo de la hasta entonces practicada. ${ }^{34} \mathrm{El}$ comercio

27 Ibídem, f. 14. Tras el fallido nombramiento de Bernardo Sancho Larrea, Vicente Azcuenaga y Francisco Segurola, el Consulado de Lima designó como apoderado a Tomas Sáenz de la Peña.

28 Ibídem, f. 2 vta.

29 Ibídem, f. 19. Mediante la reunión en Junta de Comercio, efectuada tras la citación de sus tres apoderados, Manuel Rodríguez de la Vega, Bernardo Sancho Larrea y Martín de Sarratea, y la autorización del virrey, se acordó "quese Suplique de su ejecucion y cumplimiento, mediante á ser mui gravosa asu extenuado comercio..." y para ello solicitan "suspender su cumplimiento hasta tanto que el Real, y piadoso animo de SM plenamente instruido, de nuestra respetuosa y fundada Suplica, tenga a vien expedir su segunda vision y real mandato...".

30 Ibídem. Los apoderados expresaron que "el comerciante, sus dependientes, el mercader, el tendero, y el pulpero, el artesano, y el oficial mecánico, y quantos no heran vecinos, se hallaban alistados en las milicias de infantería; y los demas, sin exepción sean estas de caballería yá urbanas ya rurales" (f. 64/64 vta.) Además, por intermedio de una serie de memorias y cuentas dieron información de los gastos de Buenos Aires en su defensa desde 1784. Expresaban que ellos habían financiado a las milicias locales, a las que desde 1750 "vistió y mantubo a sus expensas este mismo comercio..." (f. $45 \mathrm{vta}$ ), haciéndose cargo tanto de su "vestuario y pagamento de sueldos vencido...” (f. 48).

31 Ibídem, f. 53/55.

32 Ibídem, f. 64. Los comerciantes expresaban que se "ha contribuido mas de tres millones de pesos".

33 Ibídem, f. 63.

34 En este sentido, la cuestión de la libre internación fue un tema recurrente. Las peticiones solicitando el levantamiento de la prohibición fueron constantes. Véanse las declaraciones del Cabildo del 23 de septiembre de 1767, AGN, Acuerdos del Extinguido Cabildo de Buenos Aires, (en adelante 
local se esforzaba, de este modo, para librarse de la tutela de Lima y generar un vínculo directo con la Corona que le permitiera conservar y ensanchar su posición. Su estrategia consistía en reafirmar su fidelidad y apelar a su control regional ${ }^{35}$ aludiendo a su lealtad y participación constante en la defensa de la "patria". ${ }^{36}$

El asunto del pago del gravamen sobre los metales exportados desde Buenos Aires no terminó allí. Aquellos comerciantes no se resignaron a la derrota y continuaron recurriendo a las Juntas como manifestación de su margen de poder corporativo. Para el pago de esta demanda trasladaron costos al resto de la comunidad, que debía financiar la reclamación colectiva mediante gravámenes impositivos..$^{37}$ Esta forma de recaudar ingresos no era nueva, desde 1779 las iniciativas destinadas a obtener fondos para los donativos no eran voluntarias e individuales sino colectivas, implicando el aporte de toda la comunidad más allá de su voluntad. ${ }^{38}$

Además, y debido a que el gravamen solicitado por los comerciantes limeños incluía a Montevideo, las estrategias mercantiles de la elite local para obtener ingresos aduaneros fueron extendidas también a la otra margen del río, donde fue designado un encargado de recaudar tal impuesto. ${ }^{39}$

AECBA), Serie III, tomo III, págs. 529-549; o más tarde del 25 de marzo de 1771, AECBA, Serie III, tomo IV, pág. 249. O posteriormente, un documento del Archivo de Indias encontrado y publicado por Enrique Barba: Don Pedro..., págs. 289-301, del 22 de julio de 1777 elaborado por un conjunto de comerciantes. Posteriormente, y como consecuencia de estas peticiones, Cevallos estableció, el 6 de noviembre de 1777, aún ante reclamos del virrey de Lima, el "Auto de Libre Internación", por el cual los caminos al Alto Perú quedaron formalmente abiertos para los comerciantes bonarenses.

35 AGN, IX 4-7-3, expte 3, f. 65 vta/66.Los apoderados manifestaban que el comercio daba "las mas positivas pruevas de su fidelidad amor al Rey, y ala Patria, con prontitud, constancia, y esmero en sacrificar gustosos sus personas, sus vienes, sus casas, y comercio para ocuparlos destinos, quese los ha señalado dentro y fuera de la capital...".

36 Ibídem, f. 67. Los apoderados señalaban que "Este Comercio (...) enlas urgencias del Herario nada reserva, y que sus caudales son los mas promptos para auxiliarlos ala menor insinuación deque estas Cajas se hallavan exhaustas...".

37 Ibídem, expte 4, f. 1. Así parece demostrarlo la Junta reunida el 24 de julio de 1784, de la que participaron 103 comerciantes. En ella, con el propósito de efectuar las "diligencias" correspondientes de "livertar este comercio" de tal impuesto, resolvieron "tomar dinero á premio con el qual acudir a los gastos que son indispensables para estas solicitudes." El monto de 8.000 pesos fue ofrecido por Juan Esteban de Anchorena, a un 6\% de interés anual. Para su pago se aumentaba 1/4 los derechos de exportación sobre los metales enviados a España hasta pagar la deuda pendiente. AGN, IX 4-7-3, expte 4 , f. ${ }^{\circ}$.

38 El caso de los donativos mencionado en la nota 9 de este trabajo y analizados en mi tesis de Maestría, constituyen modos de recaudar ingresos de toda la comunidad y revelan la capacidad de la elite mercantil de establecer derechos para ello derivados de la exportación de metales, cueros y otros "frutos del país". Véase Kraselsky, Javier, Los comerciantes rioplatenses..., págs. 108-117.

39 AGN, IX 4-7-3, expte. 4, f. 10. Se designaba a Plácido Antonio Gallardo como recaudador de tal porcentaje en Montevideo con el objeto de pagar lo prestado por Anchorena. 
De este modo, para hacer viable la reclamación, se estableció una derrama en las exportaciones que debían pagar quienes comerciaran por ambos puertos..$^{40}$

Con ello, recurriendo al recurso de la Junta, la elite manifestaba poseer el poder de aumentar los gravámenes locales y suplicar a la Corona, como cuerpo, contra aquello que consideraba injusto. La implantación de impuestos sobre la plata demuestra que su erogación recaía tanto en la comunidad mercantil como en la población en general. No eran unos pocos los que exportaban metales, sino que, en mayor o menor medida, participaban en ello numerosos comerciantes de diferente giro económico. ${ }^{41}$

A pesar de las súplicas y reclamos de los comerciantes, y tras las presentaciones correspondientes, la Corona, por medio de la real orden del 9 de febrero de 1785, dispuso rechazar la protesta de los comerciantes y elevar los derechos de exportación de metales tal como solicitaba el Consulado de Lima ${ }^{42}$ Esta circunstancia habría motivado a los actores locales a impulsar el fortalecimiento de su ámbito corporativo, pensando que un cuerpo institucionalizado y reconocido legalmente como el Consulado, seguramente hubiera tenido mayor margen de maniobra para terciar en su favor las disputas jurisdiccionales. ${ }^{43}$

Desde 1792 los derechos de 1 y $3 / 4 \%$ en la plata, y $1 / 2 \%$ en el oro estipulados por la Corona para los metales que se embarcasen en el Río de la

40 Ibídem. Se infiere de los recibos firmados por Anchorena recibiendo porcentajes estipulados en la Junta de Juan Pedro Aguirre, (f. 30), Rafael Joseph Riglos, (f. 31) y Pedro del Barco, (f. 32) Martín de Vidarieta, (f. ${ }^{\text {2 } 23) ~ e n t r e ~ o t r o s . ~}$

41 Véase Jumar, Fernando: "Los comerciantes rioplatenses: su participación en el comercio legal español. 1720-1778”, en: Seminario Mercantilismo y Comercio en el Mundo Ibérico, Universidad Argentina de la Empresa, Buenos Aires, 2001, págs. 1-29; del mismo autor "Los rioplatenses...".

42 AGN, IX 4-7-3, expte 3, f. 91. Por intermedio de José de Gálvez, el 9 de febrero de 1785 una notificación establecía que "Ha resuelto Su Majestad (...) y hasta que ese erario (se refiere al Consulado de Lima) satisfaga la cantidad del millon y medio de pesos, se exija y cobre dicho arbitrio por el Encargado, o Apoderado del Consulado de toda la plata y el oro que en ambos puertos se embarque...".

43 El 29 de diciembre de 1785, los apoderados Manuel Rodríguez de la Vega y Martin de Sarratea, escriben a Diego Paniagua, uno de los representantes ante las Cortes, expresándole que presente un memorial al rey para lograr "la entera extinción del principal y reditos del millon y medio que tomó á interes para la expedición al mando de Cevallos...”; en este sentido, desde las gestiones para la fundación del Consulado en la Junta del 7 de julio de 1785 reseñadas en la nota 14 de este trabajo, los comerciantes de Buenos Aires habían intentado que de allí en adelante se reconociera la autonomía lograda desde la formación del nuevo Virreinato respecto a Lima y "para que cese esta contribución inmediatamente que con ella ó la que en adelante mande exigir se complete por nuestra parte la cantidad en que disponga pensionarnos.” AGN, Consulado de Buenos Aires, Antecedentes.. Tomo I, págs. 87-88. 
Plata, se redujeron al $1 \%$ y $1 / 4 \%$ respectivamente. ${ }^{44}$ Los comerciantes locales agrupados en Junta revelaban con ello contar con un margen importante de poder, mientras que la elite mercantil en su interior demostraba capacidad de negociación y la fuerza de su representación. La Corona pareció buscar con esta medida un equilibrio para no perder aliados ni profundizar conflictos que perjudicaran la sensible armonía entre las regiones y sus corporaciones mercantiles, al tiempo que manifestaba reconocer el rol hegemónico local del cuerpo de comercio de Buenos Aires. En este sentido, con el objeto de obtener ingresos monetarios, la alianza con la elite que controlaba esta corporación se revelaba como indispensable.

El cuerpo de comercio y esa elite que controlaba las Juntas manifestaban su fidelidad y margen de poder para solicitar beneficios. En contraprestación a su lealtad, la Corona reconocía y aceptaba sus requerimientos. ${ }^{45}$ Así, desde 1779, ese sector legitimaba la autoridad real, y le aseguraba sus aportes monetarios, que podían recaudarse de los derechos de exportación, como en este caso, o mediante donativos derivados de aportes colectivos de toda la comunidad.

Estas relaciones entre los comerciantes locales y los agrupados en el Consulado limeño, terciada por la monarquía borbónica, exponen, en mi opinión, la primera razón que motiva a los comerciantes a la gestión del Consulado. Si bien las Juntas y su estructura permanente se habían manifestado como recursos exitosos de defensa de sus intereses, estos conflictos jurisdiccionales con sus pares limeños revelaban la necesidad de un cuerpo orgánico y poderoso que sólo la institucionalización legal centrada en el Consulado podía brindar. Esta razón no fue la única: el conflicto con el gremio de los hacendados por la comercialización de cueros y por la hegemonía regional parece ser otra vía de análisis.

\section{Cueros, jurisdicción y Juntas: el conflicto con los hacendados}

En una sociedad de Antiguo Régimen como la que se está considerando, en la que primaba la desigualdad social, los individuos estaban integrados en corporaciones jerárquicamente ordenadas, articuladas mediante especializa-

44 AGN, IX 4-7-3, expte. 5. Levene, Ricardo: Investigaciones..., pág. 297; Tjarks, Germán: El Consulado de Buenos Aires..., pág. 33.

45 Estos vínculos de fidelidad y protección entre los actores locales y la Corona han sido analizados por Fernando Jumar en "El precio de la fidelidad...". 
ciones socioprofesionales, ${ }^{46}$ que, a pesar de no ser cuerpos cerrados y estáticos, pueden identificarse en el análisis como sectores que defendían intereses específicos. En la noción de centralización corporativa que intentamos llevar adelante, cada grupo tiene sus pautas de acción gremial y de defensa de sus intereses, que lo representan ante los demás actores de la sociedad como cuerpo. Los comerciantes no fueron los únicos actores que recurrieron a las Juntas y que tuvieron apoderados permanentes, los hacendados también las convocaron y tuvieron una organización representativa similar. ${ }^{47}$

Los hacendados poseían los ganados que abastecían la ciudad para su consumo de carne y los cueros que se exportaban hacia España. ${ }^{48}$ Precisamente esto último originó un conflicto entre comerciantes y hacendados por el monopolio de su comercialización. Si bien podría verse este choque como la disputa entre comerciantes "puros", por un lado, y comerciantes ligados a las propiedades rurales y agrícolas que protegían sus derechos de propiedad (donde los cueros eran la esencial fuente de riqueza), por el otro, aquí se opta por diferenciarlos con base en su principal actividad, la más rentable para su conveniencia y la que les permitía acceder a las experiencias concretas que los llevaban a identificarse con su grupo de pertenencia. ${ }^{49}$

Teniendo en cuenta las particularidades económicas del Río de la Plata en el siglo XVIII, los hacendados constituyeron un sector de gran importancia y de constante crecimiento. ${ }^{50}$ Igual que los comerciantes, éstos recurrieron a las Juntas como un ámbito en el cual delinear sus estrategias y proteger

46 Para un análisis de los diferentes sectores en la sociedad americana, véase Hoberman, Louisa y Socolow, Susan: Ciudades y Sociedad en Latinoamérica Colonial, FCE, Buenos Aires, 1992.

47 Sobre el tema del gremio de hacendados existen dos excelentes trabajos con abordajes diferentes. Véase Fradkin, Raúl: "El Gremio de los Hacendados en Buenos Aires durante la segunda mitad del siglo XVIII", Cuadernos de Historia Regional, n. ${ }^{\circ}$ 8, Luján, 1986, págs. 72-96; Azcuy Ameghino, Eduardo: La otra historia. Economía, Estado y Sociedad en el Río de la Plata colonial, Imago Mundi, Buenos Aires, 2002. Estos trabajos no son los primeros sobre esta cuestión pues desde Mitre, Bartolomé: Historia de Belgrano y de la Independencia Argentina, 4 vols., Ediciones Estudi, Buenos Aires, 1947 en adelante, el tema ha sido analizado, pero debido a su claridad en la exposición serán aquí tomados como punto de referencia en esta cuestión.

48 Silva, Hernán Asdrúbal: "El cabildo, el abasto de carne y la ganadería. Buenos Aires en la primera mitad del siglo XVIII": Investigaciones y ensayos, N. ${ }^{\circ}$ 3, Buenos Aires, 1967, págs. 3-72. Jumar, Fernando y Kraselsky, Javier: "Los rioplatenses y los cueros vistos a través del Cabildo de Buenos Aires durante el siglo XVIII”, XX Jornadas de Historia Económica, Universidad Nacional de Mar del Plata, Mar del Plata, 18 al 20 de octubre de 2006, págs. 1-35.

49 Azcuy Ameghino, Eduardo: La otra historia..., págs. 141-163.

50 Véase, entre muchos otros, Levene, Ricardo: Investigaciones..., págs. 300-325; Fradkin, Raúl y Garavaglia, Juan Carlos (editores): En busca de un tiempo perdido. La economía de Buenos Aires en el país de la abundancia 1750-1865, Editorial Prometeo, Buenos Aires, 2004; Fradkin, Raúl: "El Gremio de Hacendados..." y Azcuy Ameghino, Eduardo: La otra historia... 
sus intereses corporativos. ${ }^{51} \mathrm{Si}$ bien los hacendados no eran el grupo dominante en la economía rioplatense en el siglo XVIII (estando en una posición subalterna - hasta por lo menos la década del 1790 — con respecto a los grandes comerciantes), es cierto también que contaban con una riqueza sólida, basada en la tenencia de tierras y los productos agrícolas y ganaderos. Los hacendados no eran los grandes terratenientes que serán luego en el Rosismo, ${ }^{52}$ pero tenían poder de decisión como conjunto en el Cabildo, por ejemplo, donde irían lentamente consolidando su poder e influencia. ${ }^{53}$

En relación a ello, el robo del ganado y la permanencia de mercachifles y pulperos en las zonas rurales fueron problemas que los hacendados reclamaron solucionar repetidamente. ${ }^{54}$ En este sentido, la aplicación de un bando por la comercialización de cueros desató, desde 1791, una serie de conflictos latentes por la hegemonía regional. ${ }^{55}$ Dicha tensión, que manifestó el grado más alto de corporativización y organicidad del gremio de comerciantes, contuvo tres problemas interdependientes. El primero relacionado con la súplica del bando en cuestión, y los dos restantes con la

51 Éstas habrían estado relacionadas con el abasto de la carne primero y con la comercialización de cueros más tarde. AECBA, serie III tomo IV, págs. 165; 167; 244; 453-457; 463. También Fradkin, Raúl: "El Gremio de Hacendados...” y Azcuy Ameghino, Eduardo. La otra historia...

52 Ver, en ese sentido: Gelman, Jorge: Campesinos y estancieros. Una región del Río de la Plata a fines de la época colonial, Buenos Aires, Editorial Los libros del Riel, 1998; Garavaglia, Juan Carlos: Pastores y labradores de Buenos Aires. Una historia agraria de la campaña bonaerense, 1700 1830, Buenos Aires, Editorial La Flor, 1999 y Garavaglia, Juan Carlos y Fradkin, Raúl, En busca de un tiempo perdido... Estos autores analizan que no hubo, durante el Virreinato, la concentración de la propiedad que puede advertirse en el siglo XIX, destacándose las estancias pequeñas o medianas. En ese contexto, el ganado vacuno no era la principal riqueza de la sociedad rural, siendo superado por la producción agrícola. Cabildo..."

53 Jumar, Fernando, y Kraselsky, Javier: "Los rioplatenses y los cueros vistos a través del

54 Azcuy Ameghino, Eduardo. La otra historia..., págs. 94-97.

55 AGN, IX 4-7-3, expte 21, f.1/3 y Archivo Histórico de la Provincia de Buenos Aires (en adelante AHPBA), 7-2-108/6, cuerpo III. El 12 de septiembre de 1791, el virrey Arredondo publicó, a solicitud de los hacendados, un bando que buscaba evitar el robo y la venta clandestina de cueros. Dicho bando, si bien no fue el primero en esta dirección, produjo el recrudecimiento de un conflicto latente entre los comerciantes y hacendados por el acaparamiento y control del mercado y la venta de cueros Se establecía que "todos los cueros, que en calidad de comprados porla campaña se conduscan a las Barracas, quintas o casas de esta capital ademas de venir con las certificaciones y guias (...) se hande introducir de dia claro y a tiempo que puedan reconocerse por dicho Apoderado como Comisionado de esta Sup. Gov. Y demas personas que a ello se destinen (...) si entre ellos se encontrase aunque sea uno solo sin la certificación y guia correspondiente se daran todos por perdidos...”. Establecía además una serie de obligaciones, por ejemplo que los criadores ante cada venta, donación o pago debían contramarcar los cueros y declarar cuándo y a quién los transferían; estas transferencias debían contar con la aprobación del alcalde del partido, con lo cual se controlaba el ingreso a las barracas. También se establecía la necesidad de marca que certificara quienes eran sus dueños, penando su copia. En otro artículo se prohibía la matanza de ganado ajeno. 
acción del gremio mercantil contra los representantes del cuerpo de los hacendados, Juan Ximenez de Paz y Antonio de Obligado. ${ }^{56}$

Por el primero, la posibilidad de perder todos los cueros por sólo uno fuera de regla, y el control del apoderado de los hacendados sobre la carga de cueros que los comerciantes exportaban produjo la reacción mercantil y la convocatoria a Juntas. Así, los apoderados de los comerciantes Martín de Sarratea y Manuel Rodríguez de la Vega convocaron a una Junta de Comercio el 17 de septiembre de 1791 con el fin de elaborar estrategias colectivas de acción ${ }^{57}$ y gestionar mediante esas acciones la reforma del bando. ${ }^{58}$

Los comerciantes consideraban que, debido a que muchos de los cueros que adquirían no tenían marcas, la sanción proyectada podía provocar la ruina de los dedicados a tal actividad..$^{59}$ En este sentido manifestaban una clara desconfianza hacia los hacendados que debían controlar su comercialización. ${ }^{60}$ Esto motivó que los primeros, desde la última década del siglo XVIII y ante el temor y la amenaza que representaban los hacendados, impulsaran con más fuerza la gestión de su Consulado. ${ }^{6}$

La protesta de los comerciantes obtuvo un resultado favorable, aplicándose provisoriamente reformas al bando el 5 de marzo de $1792 .{ }^{62}$ Con

56 Estos problemas han sido analizados desde la perspectiva del cuerpo de hacendados por Azcuy Ameghino, Eduardo: La otra historia..., especialmente págs. 117-135; 141-162.

57 AGN, IX 4-7-3, expte 21, f. 4/4vta y AHPBA, 7-2-108/6, cuerpo III.En esta Junta participaron 97 comerciantes que designaron, además del apoderado Martín de Sarratea, a Martín de Alzaga y Francisco Casimiro de Necochea como "asociados" con amplias facultades para representar al conjunto y efectuar las gestiones necesarias ante las autoridades virreinales.

58 Ibidem, f. 7. Con dicho objeto realizaron una presentación firmada por los 97 comerciantes que participaron en la Junta mencionada en la nota anterior. Allí, los comerciantes observaban que el perjudicado con tal bando sería "el comerciante inocente" que "tubo la desgracia deque el odio, el interes ó la Tramoya le jugaren en una pieza para damnificarlo...".

59 AHPBA 7-2-108/6, cuerpo III, f. 12. Los comerciantes alegaban que los hacendados se valían de "Apoderados capataces y peones dela infima clase para la conducción (...) nada es mas facil a cualquiera de los peones, o delos reconocedores al tiempo de reconocerlos (...) meter entre ellos con disimulos, algunos, alguno ó algunos de exceso para tener ocasión de denunciar toda la partida...”.

60 Ibídem, f. 16. Exigían que una vez introducidos los cueros en las Barracas, nadie podría "ingerirse con algun proposito a estos depositos, limitandoseles el ejercicio detoda su actividad, celo y esmeros al acto de la introducion, y cumplimiento delas Guias".

61 AGN, IX 4-7-3, expte 21, f. 20/21. En pleno conflicto con los hacendados, Martín de Sarratea, Casimiro Francisco Necochea y Martín de Alzaga, en nombre del comercio, intercambiaron cartas con Diego Paniagua y Tomás Arroyo, representantes del comercio en Madrid, con el objeto de acelerar la gestión para la creación del Consulado.

62 AHPBA, 7-2-108/6, cuerpo IV, f. 8 vta. Se mantuvieron los requisitos de las contramarcas, pero se circunscribió la autoridad del reconocedor de cueros. Una vez entrados los cueros en la barraca o almacén para embarcar, no podían volver a reconocerse a menos que se justificara con la presencia de dos testigos. 
ello, la respuesta de los hacendados no se demoró y los conflictos entre ambos gremios continuaron..$^{63}$ En este contexto, el monarca por real cédula, encomendó su resolución a la Real Audiencia. ${ }^{64}$ Más tarde, y en el marco de las disputas, el 9 de agosto de 1793 se efectuó una nueva Junta de Comercio para continuar la súplica del bando de Arredondo. ${ }^{65}$

Los impulsos por parte de los comerciantes para establecer el Consulado se hicieron más fuertes. Esperaban que la fundación de dicho tribunal terciara a favor del comercio consolidando su posición regional privilegiada. Así, Diego Paniagua, representante del comercio en Madrid, en carta al apoderado y sus asociados el 1 de agosto de 1793, expresaba las "siniestras intenciones de algunos", en alusión a Antonio Obligado, representante de los hacendados, y que

"Se esta trabajando en las Cedulas sobre Establecimientos de Consulados (...) no pierdo ni perderé de vista un instante, pues contemplo que sin este Tribunal tan util, todos los dias estaran llenos de Historias y Camorras como la presente". ${ }^{66}$

Con la instalación del Consulado de Comercio en 1794, la cuestión adquirió nuevas dimensiones. Debido al alcance temporal y metodológico propuesto en este trabajo, no se ahondará en el problema. Baste aquí enunciar que el gremio de comercio obtuvo la modificación de los artículos conflictivos del bando ${ }^{67}$ El Consulado, solicitado con mayor ímpetu desde principios de la década de 1790, se revelaba como el instrumento más efi-

63 Ibídem, f. 10-10 vta. Los hacendados acusaban a los comerciantes del robo, "les es indiferente que sean los comerciantes, ò sus dependientes almaceneros y barranqueros...". Consideraban que si no hubiera quien les comprase los cueros "no se dedicarian con tanto empeño a sacarlas con no menos detrimento de los dueños, que del publico y aun del comercio mismo".

64 AGN, IX 4-7-3, expte 21, f. 23 vta/24. El 1. ${ }^{\circ}$ de diciembre de 1792 el rey mandó a que la Real Audiencia, "oyendo al cuerpo de Hacendados, al de Comercio, al Cabildo Secular y al ministerio fiscal, se determine lo mas conveniente...”.

65 Ibídem, f.27-2 vta. De ella participaron 20 comerciantes, y se aludió a la situación en que se encontraba la gestión de la causa criminal seguida contra Ximenez de Paz y Antonio Obligado, representantes del gremio de hacendados. La Junta aprobó lo realizado por sus representantes y justificó sus quejas contra los citados hacendados ampliando las facultades de los diputados del comercio encargados de esta cuestión.

66 Ibídem, f. 29.

67 AHPBA, 7-2-108/6, cuerpo I, f. 95-106. Desde septiembre de 1794 al 5 de marzo de 1796, se desarrolló esta problemática que incluye oficios del Cabildo, la Audiencia y el Consulado. Los mayores perjudicados parecen ser los pulperos y tenderos, que son señalados como responsables de robos, y a los cuales debía controlarse con mayor vigor. Así se refleja en un oficio de Cristóbal de Aguirre, síndico del Consulado en enero de 1796. En 1795 los comerciantes persistieron con sus reclamos, así lo demuestra una carta firmada por 16 de ellos, en la que deslindaban su responsabilidad en los robos y exigían mayor dureza contra los reconocedores. Ibídem, cuerpo VII, f. 2/6. 
caz para la conservación del equilibrio centrado en la hegemonía de los comerciantes. A su vez, la cesión de la Corona de tal institución, revelaba también su necesidad de aliados poderosos que le asegurasen la recaudación de sus ingresos. De este modo, la creación del Consulado de Buenos Aires puede analizarse como la consecuencia de la negociación entre los actores corporativos que buscaban beneficios mutuos y la conservación del equilibrio que lo permitiera.

Paralelamente a la súplica del bando, el comercio local siguió, como ya se ha anunciado, dos disputas con los referentes de los hacendados. La primera contra Juan Ximenez de Paz, apoderado de estos propietarios de tierras y reconocedor de cueros, quien era acusado por el cuerpo de comercio de efectuar estafas y extorsiones. ${ }^{68}$ Para desacreditarla, los comerciantes impulsaron una serie de estrategias que atacaban tanto su idoneidad personal como su trabajo referente a los cueros. ${ }^{69}$

La segunda, más compleja, se siguió contra Antonio Obligado, ${ }^{70}$ que asistió a la Junta de Comercio reseñada del 17 de septiembre de 1791, negándose a participar con su firma en la súplica. ${ }^{71}$ Obligado expuso de modo claro los perjuicios del cuerpo de hacendados y atacó a los comerciantes quienes, en su opinión, en su afán de enriquecerse no distinguían los cueros legales de los ilegales. Observaba que éstos últimos adquirían el cuero "de las manos de que los roban, y de otros que tienen Almacenes y Barracas, y en ellas los van acopiando para vender por mayor...". ${ }^{72}$ Tanto comerciantes, como pulperos y mercachifles participaban, según su criterio, de tales perjuicios.

Obligado responsabilizaba a los comerciantes del robo y de los perjuicios que sufrían los hacendados en la obtención de mano de obra. Consideraba que con su indulgencia apañaban a los vagos y faenadores del

68 Ibídem, cuerpo I, f. 2.

69 AHPBA, 7-2-108/6, cuerpo II. Mediante testimonios de 14 comerciantes presentados entre marzo y abril de 1792, el cuerpo mercantil señalaba los fraudes constantes que sufrían estos para "evitar demoras", y que 4 de ellos, le habían prestado sumas de dinero sin recibir su devolución.

70 AHPBA, 7-2-108/6, cuerpo III, f. 23. Obligado se autodenominaba "Vez.no y del comercio de esta Ciudad, hacendadode la Campaña, y rematador de los Diezmos dela Quentropea delos Partidos de los Arrecifes y Magdalena...".

71 Ibídem, f. 23 vta. Ello significaba, según Obligado, "ladestruccion y exterminio de las haziendas de Campaña, con los gravisimos perjuicios que sufren los haz.dos..." por ello no podía menos que "impugnar, como vecinoy haz.do de la Campaña" tal iniciativa., expresaba que, en su opinión, la súplica de los comerciantes abrigaba la continuación de los robos con la consecuente decadencia de sus actores y del Estado.

72 Ibídem, f. 24. 
campo. ${ }^{73}$ Además, señalaba que muchos de éstos sabían y evitaban su responsabilidad en tal acto ingresando "adeshoras y huyendo de que los vean (teniendo) pocos escrupulos en comprarlos y recibirlos...". ${ }^{74}$

En este sentido, señalaba que la reclamación de los comerciantes era injusta, y de prosperar podría llevar a la ruina no sólo de los hacendados sino de la provincia. ${ }^{75}$ Obligado, con el propósito de transformar a los hacendados en el sector más poderoso y de desplazar a los comerciantes de su posición de nexo entre las autoridades y las producciones locales, atacaba a los segundos en su constitución y origen. ${ }^{76}$

Así, Obligado se inclinaba decididamente hacia una de sus actividades, y criticaba al seno de la Junta de Comercio, a la que consideraba ilegítima. En alusión a la reunida el 17 de septiembre de 1791, observaba que

\begin{abstract}
"Si se cita a Junta para tratar asuntos interesantes al comercio, se debe proponer lo q se ofresca, dexar libre el dictamende cada uno y escribirlo, sea ono conforme ala idea delos que pretenden, y después hagan sus Representaciones; para que viendo los pareceres detodos, pueda examinar y resolver lo que sea mas arreglado a Justicia. Pero citar a Juntas para que apoyen Representaciones ya forxadas a idea de particulares fines, y no solo no admitir el dictamen delos qe no se conforman sino guardarlos para un delito, no es citar atratar ni á acordar, sino buscar protectores de las pretensión, afin de juntar muchas firmas, para que la multitud de conformes Suplicantes incline el animo del Superior aconsiderarla justa; y acaso muchos no firmarian siles diesen tiempo de examinar los auntos, otros dirian que firmaron porque les dixeron qe era asunto de comercio, como siel comercio nose compusiera de hombres capaces de errar y pedir una injusticia". ${ }^{77}$
\end{abstract}

La respuesta de los comerciantes fue del mismo tenor. Rechazaron todos los argumentos de Obligado y tildaron a su Representación de "libelo". Consideraban que éste justificaba sus ataques bajo el rótulo de comer-

73 Ibídem, f. 25. En una representación del 30 de septiembre de 1791, Obligado observaba que la campaña estaba "infestada de vagos y gente pobre, no quieren conchavarse porque les hace mas cuentarobar un Cuero cada dia qeganar seis pesos al mes y si no tuvieran les recibiese el Cuero, se verian precisados a sugetarse al trabajo y sobrarian peones...".

74 Ibídem, f. 24 vta.

75 Ibídem, f. 31. Los comerciantes, según Obligado, debido a su ambición desmedida agotarían los cueros de las zonas rurales. Luego el gremio de comerciantes "tardaría poco en desgranarse en busca de su particular interes a otras Provincias siseles permitiera como pretende arruinar esta de un solo golpe....".

76 Ibídem, f. 26 vta. Observaba que "los hax,dos sontodos Vez.nos del Pueblo, o la Campaña aqe sirven defomento los fondos qe adquieren" los comerciantes, en cambio, "ni todos son Vez.nosnitodos utiles ala Provincia. Muchos son forasteros aquienes ha trahido y detiene su solo particular interes y el objeto de ganancias...".

77 Ibídem, f. 29 vta. 
ciante, vecino y hacendado, para "honestar (...) su oficiosa ingerencia" 78 cuando en realidad sólo actuaba en nombre de los últimos y en perjuicio del comercio. El propósito del apoderado Martín de Sarratea y sus "asociados" era deslegitimar a Obligado como representante de los hacendados, reafirmando la condición del gremio de comercio como "cuerpo privilegiado" y de las Juntas como su recurso legítimo de acción.

Así, ante tan agudos ataques, la estrategia mercantil inicial consistió en incluir a Obligado como parte del cuerpo de comercio. De este modo, proyectaban quitarle el rol de hacendado que manifestaba en su Representación. Para ello observaron que atacaba a "su cuerpo de comercio", y actuaba "en ultraje del honor, reputacion y privilegios del mismo cuerpo que le dio el ser en linea de comerciante". ${ }^{79}$ Su intento era incorporar a Obligado al cuerpo de pertenencia y resolver el problema como un conflicto interno entre facciones del mismo cuerpo, como ya había ocurrido en otras oportunidades. ${ }^{80}$

Así, considerarlo comerciante también era, de alguna manera, incluirlo en las acciones que él mismo denunciaba, recordándole sus alianzas o pasado común. ${ }^{81}$ En este sentido, las Juntas desde 1779 eran reconocidas - tanto por la Corona, como por los comerciantes - como cuerpo representativo de toda la comunidad mercantil. El problema, tomado de este modo, se circunscribía al ámbito comercial, y allí, y entre pares, debía resolverse.

Mediante esta estrategia, solicitaban el pago de Obligado de 20.000 pesos por calumnias. Éste, lejos de retractarse, redobló la apuesta con sólidos argumentos que dejaban en claro su desapego respecto del cuerpo de comercio y su estructura política. Su propósito era impulsar el ascenso de los hacendados como cuerpo aliado a la Corona en reemplazo de los comerciantes.

Para ello atacó a los segundos y a la legitimidad de sus recursos de acción. Su estrategia buscaba quebrar el argumento de representatividad de los apoderados del conjunto del comercio, manifestando en cambio la ver-

78 Ibídem, f. 42 vta.

79 Ibídem, f. 44.

80 AGN, IX 4-7-3, expte 22. Muchas Juntas revelan su iniciativa para gestionar la resolución de problemas entre las facciones mercantiles. Como ejemplo de ello puede mencionarse el conflicto entre un grupo de comerciantes y Tomás Antonio Romero por la exportación de "frutos del país" y la introducción de esclavos.

81 AHPBA, 7-2-108/6, cuerpo III, f. 97. En este sentido, según Obligado fue propuesto como "consiliario" en la Junta de 1785 en que se impulsaba el Consulado. 
ticalidad de sus acciones. Con este propósito, Obligado envió entre el 29 y el 30 de octubre de 1792, una serie de cartas, solicitando a los comerciantes que supuestamente participaron en la Junta del 17 de septiembre de 1791, información sobre ella y sobre su voto. Éstos, que aparecían como firmantes, confesaron no haber participado de ella. ${ }^{82}$ Todo esto demuestra la organicidad con que se desempeñaba el cuerpo de comercio, legitimando los comerciantes las decisiones del sector poderoso que controlaba el gremio.

La ofensiva de Obligado y los hacendados se dirigía precisamente a demostrar lo ficticio de la representatividad y autoridad colectiva de sus adversarios. Manifestando su falta de legitimidad, circunscribían el reclamo colectivo a sólo una demanda particular de comerciantes poderosos que se atribuían potestades de conjunto. Por otro lado, y continuando con su estrategia de acción, Obligado gestionó ante las autoridades la revisión del pago de alcabalas y los ingresos de aduana que comprometieron la integridad del cuerpo de comercio. ${ }^{83}$

Es decir, la estrategia de Obligado revela que las Juntas de Comercio estaban controladas por un sector poderoso que se atribuía potestades colectivas, lo que permite conjeturar que fue este sector el que, con el propósito de conservar su hegemonía, habría impulsado con mayor fuerza la institucionalización del cuerpo mercantil en el Consulado de Comercio.

Los argumentos de Obligado se profundizaron el 22 de febrero de 1793, mediante una nueva Representación contra el comercio, su estructura política y la legitimidad de su representación. Desconocía en ella no sólo la Junta del 17 de septiembre de 1791, sino más aún el recurso a Junta practicado por sus adversarios. Planteaba que asistió a dicha reunión observando "la ninguna formalidad con que se procedia", en la que no se discutió ni se escuchó a todos, ni se dio tiempo para que cada uno meditase el problema. Señalaba que

82 Ibídem. Los comerciantes que confesaban no haber participado son Manuel Ferreira de la Cruz (f. 51), Josef Escudero (f.52), Manuel Antonio Hermua (f. 53), Juan Antonio Lezica (f.54) y Pablo Sartores (f. 55). Según Obligado, otros "le han respondido verbalmente qe no" f. 74 vta. como Joaquin Pintos (f. 100 vta); Josef Antonio Cabral (f. 101); Pablo Ruiz de Gaona (f. 102); Josef Santos Inchaurregui (f. 103)

83 Ibídem, f. 67. Ángel Izquierdo, Contador de la Real Aduana, declaró que durante el año 1790 entraron a la ciudad 151.050 cueros, saliendo para Montevideo con destino a España 332.401 cueros; en el año 1791 entraron 162.516 cueros, saliendo en la misma forma 280.953; y hasta el 30 de septiembre de 1792, habían entrado 215.257 cueros, saliendo 432.231. 
"se reducia aquel acto a sorprender y conciliar los animos de los comerciantes, para que apoyasen y firmasen después la ya forxada Representación, leyda repetidas veces con tal andar, que despedia sobraba luz para conocer el objecto de la citación, y los animos de sus autores..." ${ }^{84}$

La rapidez, la organización y sistematicidad con que se resolvían las cuestiones en la Junta eran también objeto de crítica de Obligado, quien dijo haberse opuesto a ello y quejado en público. De este modo, cuestionó la falta de reacción de los comerciantes que silenciosamente legitimaban la acción de los apoderados. Obligado señalaba que se negó a firmar la Junta,

"pues por mas que yo sea Comerciante, no debo ni puedo en conciencia dexarme arrastrar delos intereses que mis dictamenes puedan proporcionar al comercio, y mucho menos a sus particulares Individuos, sin examinar primero silos medios de que pretenden valerse para conseguirlos producen como perjuicios al publico, al estado o a otro gremio". ${ }^{85}$

Él mismo, si bien se denominaba comerciante, desconocía la legitimidad del cuerpo mercantil, y sobre todo de su apoderado Martín de Sarratea, "a quien principalmente [se] dirige minarracion". Además observaba que los firmantes no concordaban con los asistentes y que algunos no se dedicaban al comercio de cueros con España. En esta dirección, primero Obligado y luego su apoderado Francisco de Alba, no sólo desconocieron esta Junta, sino también a su escribano, a quien acusaban de reunir las firmas con posterioridad al hecho, poniendo en duda todas las Juntas a las que había asistido. ${ }^{86}$

Las pretensiones del comercio, en opinión de Obligado, permitían "la continuación de los robos, con permiso de abrigar los deque los Ganados se extingan, los hacendados se arruinen, de que la Provincia peresca, y que el Estado decaiga..." el comercio "ciego por el interes aqe depresente aspira, pretende su destrucción en este Pais". ${ }^{87}$

También desestimaba Obligado las amenazas de pago impulsadas por el comercio. En su opinión, los apoderados y los "secuaces" que lo acusaban no poseían legitimidad para hacerlo; consideraba que "la Junta no fue

84 Ibídem, f. 70 vta.

85 Ibídem, f. 70 vta.

86 Ibídem, f. 75 y f. 140.Obligado lo cuestionaba, ya que muchos no estaban allí cuando se firmó; de Alba, con una visión más radical, observaba que a dicha Junta sólo asistieron 28 individuos y firmaron 96, con lo cual el escribano que legalizaba las firmas actuaba como parte del comercio.

87 Ibídem, f. 77 vta. 
de Comercio, sino de firmas..." ${ }^{88}$ En este sentido, fue un enemigo acérrimo precisamente porque, como antiguo integrante del cuerpo, conocía los artilugios y estrategias seguidos por sus miembros.

Ante esta nueva circunstancia, el cuerpo de comercio replanteó su estrategia inclusiva inicial y se propuso otra que excluyera a Obligado del cuerpo de comercio y proyectase un ataque frontal y abierto contra el gremio que éste representaba. La disputa continúa mediante las representaciones cruzadas entre Pedro Josef Bervel, "anombre del comercio de esta capital", y Francisco de Alba como representante de los hacendados.$^{89}$ En ellas se manifestaron acusaciones sobre la legitimidad de una y otra Junta y sobre la autoridad nominal de sus representantes. Ello trasciende el marco temporal que este trabajo plantea, ya que prosigue una vez fundado el Consulado.

Este conflicto entre sectores revela también una señal para explicar la tardía incorporación del gremio de hacendados al Consulado de comercio. ${ }^{90}$ La disputa sobre la hegemonía local quedaba con ello saldada, el comercio se erigió como el sector más poderoso, árbitro de los problemas internos y aliado de la Corona en su propósito de obtener ingresos americanos. Así, los hacendados serían, en primera instancia, relegados del Consulado.

Además, en esta coyuntura se habría producido un quiebre en el mismo universo mercantil en donde los comerciantes poderosos, una vez creado el Consulado, habrían subestimado el apoyo de los pequeños comerciantes y tenderos que legitimaban su proceder mediante la Junta, relegándolos de los beneficios. En este sentido, puede pensarse que tras la creación del Consulado y de la tardía incorporación de los hacendados, estos dos cuerpos y sus elites poderosas habrían conformado, pocos años más tarde, una nueva alianza. Las acusaciones a pulperos y mercachifles parecen ser el punto de equilibrio que permitiría ese nuevo acuerdo.

\section{Conclusión}

Este trabajo se propuso analizar las estrategias de los comerciantes rioplatenses agrupados en las Juntas de Comercio durante el último cuarto

88 Ibídem, f. 98 vta.

89 Ibídem. Ellos, en representación de cada sector, se atacaban mutuamente y entrecruzaban sus amenazas.

90 Azcuy Ameghino, Eduardo: La otra historia..., págs. 76-78. 
del siglo XVIII. La elite mercantil que controlaba dicho ámbito de negociación y que representaba al conjunto de los comerciantes ante la Corona y el resto de las corporaciones motivó con mayor énfasis desde principios de la década de 1790 la conformación del Consulado para resguardar su hegemonía regional y privilegios económicos.

Desde 1779 y hasta 1794 los comerciantes poseyeron una estructura permanente de representación compuesta por apoderados que tenían como función proteger los intereses colectivos y gestionar, con ese fin, las medidas resueltas en la Junta. Estas Juntas y su organización política constituyeron un espacio reconocido por las autoridades reales y consensuado por la comunidad mercantil en su conjunto.

Las primeras aceptaban y reconocían esta organización para obtener, mediante su alianza con los sectores poderosos locales, ingresos monetarios y la conservación de su autoridad nominal en territorios tan lejanos al control directo. De este modo, la Corona estimulaba la corporización de los sectores de poder para negociar a través de ellos los beneficios y mutuas contraprestaciones. Los comerciantes locales aceptaron esta propuesta, conformando en primera medida su organización semiformal desde 1779, y posteriormente negociando la institucionalización del Consulado plasmada en 1794.

Por otra parte, la comunidad mercantil aceptaba y legitimaba las Juntas de Comercio y su organización permanente, ya que de este modo podía obtener beneficios laterales, como por ejemplo dilaciones en el pago de impuestos. Es decir, los comerciantes como conjunto constituían un cuerpo con su propio margen de poder que, lejos de estar subordinado al poder central, podía negociar sus beneficios y lealtades. La fundación del Consulado de Comercio puede entenderse en este contexto de negociación entre la Corona, necesitada de ingresos, y el cuerpo mercantil que controlaba los intercambios regionales y poseía la capacidad de obtener recursos del resto de la comunidad.

Han sido analizadas asimismo las razones por las cuales las Juntas de Comercio y su estructura permanente, como organización mercantil exitosa, fueron transformadas en la institución legal del Consulado. Los comerciantes locales impulsaron la formación del Consulado en una coyuntura en la cual su hegemonía regional estaba amenazada por otros actores poderosos. Mediante Juntas y representaciones, el cuerpo mercantil elaboró estrategias para resguardar su posición tanto de los comerciantes del Consulado de Lima, como del gremio de los hacendados. 
De este modo, este trabajo ha demostrado que la conformación del Consulado fue la consecuencia tanto de las iniciativas monárquicas para resignificar sus relaciones con los súbditos locales, como de las estrategias de los comerciantes rioplatenses que buscaban obtener ventajas para consolidar su posición económica. Así, por un lado, la competencia por los mercados interiores agudizó tensiones y competencias jurisdiccionales con el Consulado de Lima y esta tensión ocasionó rivalidades que estimularon a los comerciantes locales a solicitar la formación de un cuerpo legal y autónomo.

De hecho, estos últimos, obligados a descontar de sus ingresos mercantiles ciertos derechos a favor del Consulado de Lima, comenzaron a pedir cada vez con mayor ímpetu la fundación de su propio Consulado. En este sentido, el propósito de los comerciantes locales era tanto desplazar al comercio limeño de su rol dominante, como generar un lazo de unión directa con la Corona que les asegurara sus ventajas económicas.

Por otro lado, la amenaza de distintos cuerpos constitutivos de la sociedad como los hacendados, que les disputaban la comercialización de cueros y la hegemonía regional, constituyó otro de los factores que estimularon a los comerciantes a gestionar la institucionalización del cuerpo mercantil. Los segundos consideraban que los hacendados, por su creciente importancia, buscaban desplazarlos de su lugar privilegiado para obtener mayores beneficios.

En este conflicto con el gremio de hacendados, el comercio obtiene la victoria que le permite seguir hegemonizando los mercados locales y las redes de intercambio. Es decir, los comerciantes, al menos en esta época, continuaron siendo el sector prioritario con quien la Corona tuvo que negociar. ${ }^{91}$ En este sentido, puede arriesgarse que sólo desde 1797 se produjo la unificación de intereses entre sectores conflictivos y poderosos de hacendados y comerciantes en el Consulado de Comercio. Este nuevo vínculo habría significado el desplazamiento de la alianza inicial entre la elite mercantil y el resto de los comerciantes por otra alianza que incluía a los sectores de poder antiguamente enfrentados.

Estas dos razones son, en mi opinión, las que motivaron a los comerciantes a agudizar su estrategia de corporización instituida informalmente en 1779 con el establecimiento de apoderados permanentes. En este senti-

91 Esto plantearía una mayor autonomía de los comerciantes en su relación con la Corona, que superaría su condición de meros agentes del poder real. 
do, la propuesta inicial borbónica de fortalecimiento del Estado y la rearticulación de los canales de diálogo respecto a los actores locales fue aceptada y potenciada por sus sectores mercantiles que buscaban no sólo lograr nuevas ventajas, sino no perder las ya obtenidas. Su elite mercantil fue quién dominó estas Juntas y estimuló, cuando fue necesario, la institucionalización de su corporación mediante el Consulado.

Las Juntas, entonces, fueron medios en los cuales se desarrollaron las estrategias de los actores mercantiles. Fueron instrumentos exitosos de acción reconocidos por la Corona y el resto de los actores de la sociedad de Antiguo Régimen. Los comerciantes locales, como consecuencia de sus experiencias políticas y prácticas consuetudinarias, apelaron a estos mecanismos como forma de establecer un canal de diálogo con el rey. La creación del Consulado de Buenos Aires fue entonces la consecuencia de la rearticulación de las relaciones entre la Corona y las elites mercantiles que aseguró, al menos por un tiempo, beneficios mutuos. Así, sólo cuando los intereses de los actores poderosos locales estuvieron en juego, se impulsaron estrategias para fortalecer el cuerpo mercantil y la hegemonía de quienes controlaban las Juntas. Con ello Corona y cuerpo mercantil negociaban los términos de su vínculo, conservando el equilibrio que permitía a unos y a otros alcanzar sus objetivos. 